\title{
Impact of SiC Technology in a Three-port Active Bridge Converter for Energy Storage Integrated Solid State Transformer Applications
}

\author{
Zhenyu Wang, Alberto Castellazzi \\ Power Electronics, Machines and Control Group \\ The University of Nottingham \\ Nottingham, NG7 2RD, UK
}

\author{
Sarah Saeed, Ángel Navarro-Rodríguez, Pablo Garcia \\ Dept. of Elec., Computer \&System Engineering \\ University of Oviedo \\ Gijón, Spain
}

\begin{abstract}
Silicon Carbide (SiC) MOSFET power module has become commercially available in the past few years, and it is attractive in solid state transformers (SSTs) applications to replace Silicon ( $\mathrm{Si}$ )-based IGBTs. This paper is focused on the efficiency comparison between a SiC MOSFET-based three-port active bridge converter (TAB) and a Si IGBT-based approach. The efficiency of the overall system, being one of its ports connected to the energy storage element (Lithium-Ion battery), is tested and analyzed. By swapping the switching frequency of the device, a significant efficiency improvement can be observed by $\mathrm{SiC}$ power devices. Experimental results indicated that an efficiency increment of around $2 \%$ can be brought by $\mathrm{SiC}$ MOSFET. Moreover, the battery losses can be reduced by a maximum of $8 \%$ with the increased switching frequency.
\end{abstract}

Keywords-Silicon Carbide; Solid State Transformer; Threeport Active Bridge Converter; Energy Storage; Efficiency

\section{INTRODUCTION}

Recently, solid state transformer (SST) concept is becoming more and more popular. The basic idea of SST is to achieve power transfer and voltage transformation under medium/high-frequency isolation, which will lead to a significant reduction in the volume and weight compared with a conventional power transformer. Figure 1 illustrates a typical 3-stage SST topology [1]. It can be noted that the 3-stage SST can provide both high-voltage and low-voltage DC busbars, which is achieved by stage 2, also known as dual active bridge converter (DAB). The DAB converter is the key part of the recent SST to get galvanic isolation as well as voltage matching. Generally, it transforms DC voltage to AC voltage (square waveform) on the primary side of the transformer and turns back to DC voltage on the secondary side. Additionally, DAB converters also provides the flexibility to connect with energy storage systems (ESS). There are some solutions already been reported in past papers.[2] discussed a DAB converter with a dedicated DC-DC converter connected on one of its ports. [3] and [4] presented a multiport solution, also known as three-port active bridge (TAB) converter. Compared with the DAB with an extra DC-DC converter, TAB converter provides galvanic isolation to the ESS, which will lead to a higher reliability.

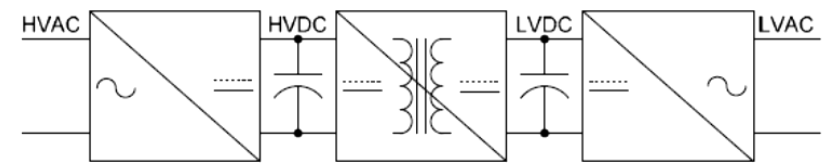

Figure 1. Typical topology of a 3-stage solid state transformer [1]

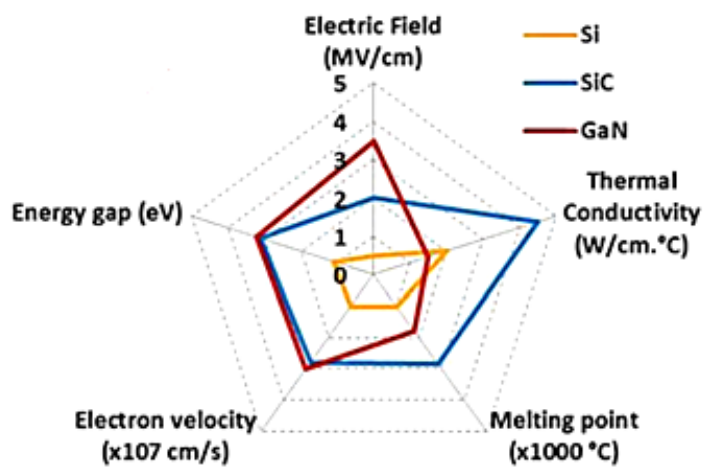

Figure 2. Summary of $\mathrm{Si}, \mathrm{SiC}$, and $\mathrm{GaN}$ on major material properties [5]

However, the relatively high switching losses as well as the highly demand in harsh environment applications, like aerospace and shipboard micro-grid, have limited the application of Si IGBT-based TAB converter. Moreover, the current commercialized SiC MOSFET power module has provided a lot of flexibility of SiC power devices to be used in such medium/high power applications. Figure 2 presents the major material properties of $\mathrm{Si}, \mathrm{SiC}$ and $\mathrm{GaN}$ devices [5]. It is clear that $\mathrm{SiC}$ has a relatively higher energy gap and higher electric field compared to $\mathrm{Si}$, which enable the $\mathrm{SiC}$ based devices operating under higher voltage. Also, the much larger electron velocity makes $\mathrm{SiC}$ power devices much easier to operate at higher switching frequency and bring lower switching losses. Additionally, the larger thermal conductivity represents the $\mathrm{SiC}$ based devices could dissipate more power under certain chip area, which contributes a lot to build a high power density converter. And lastly, the much higher melting point provides $\mathrm{SiC}$ power devices the ability to withstand higher operation temperature. The above mentioned material 


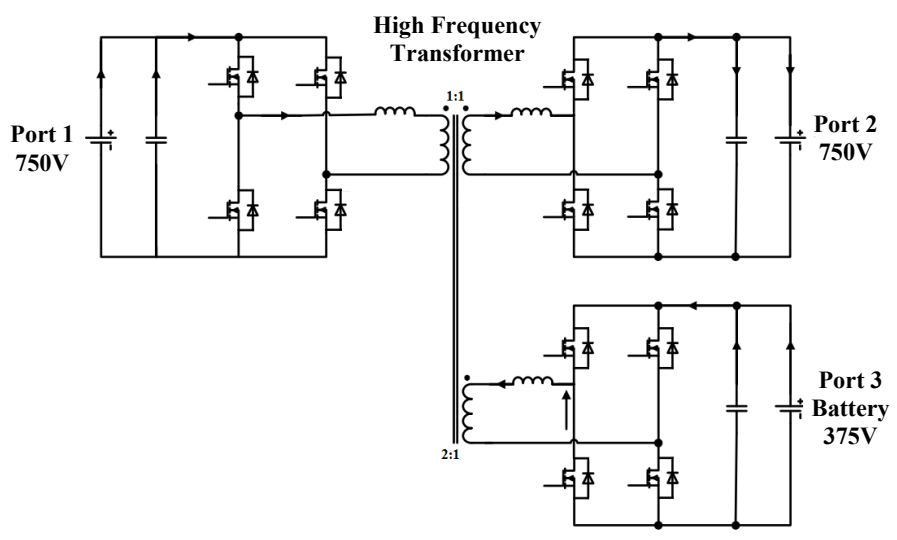

Figure 3. TAB converter structure

properties enable $\mathrm{SiC}$ power devices to be used in high voltage and/or harsh environment applications. More importantly, as a result of thinner drift regions, which because of the associated higher electric field values, the on-resistance of $\mathrm{SiC}$ based devices is much lower compared with Si based devices.

A lot of studies have been done in the application of $\mathrm{SiC}$ devices. [6] generally describes the comparison between $\mathrm{SiC}$ and Si power devices in inverter and DC-DC converter systems application. [7] analyzed the improvements that could be brought by $\mathrm{SiC}$ MOSFETs in small-scale wind energy conversion systems. [8], [9] report the application of $\mathrm{SiC}$ MOSFETs in DAB converter. It can be seen that the application of $\mathrm{SiC}$ power devices do provide a performance improvement of the whole system, the power density could be increased as well. However, few work has been done on TAB converter, even few research mentioned the influence of high switching frequency on ESS. It is believed that a higher switching frequency of $\mathrm{SiC}$ power devices would provide a better performance and higher efficiency on ESS, especially on lithium-Ion batteries [10]. Due to the inductive behavior, the losses of the lithium-Ion battery will reduce dramatically and will provide a lot of benefits to the overall system efficiency.

This paper will organize as follows. Section II will present a general description of the built TAB converter where the ESS is connected, and the employed Si IGBT and SiC MOSFET power devices will be generally discussed. Section III will include the experimental results of the built SiC-based TAB converter and Si-based approach, the efficiency under different switching frequency and power level will be calculated and compared. The efficiency of the ESS and the converter with ESS will be calculated as well in this section.

\section{SYSTEM DESCRIPTION}

\section{A. Three-port Active Bridge Converter}

A three-port active bridge, also namely triple active bridge converter, plays an important role in solid state transformer with energy storage integrated. The TAB converter topology is illustrated in Figure 3. As mentioned in Section I, one of its ports on the output side is connected to an ESS (lithium-Ion battery), and the input side of the converter is connected to a rectifier, which is used to connected to the AC main grid. The

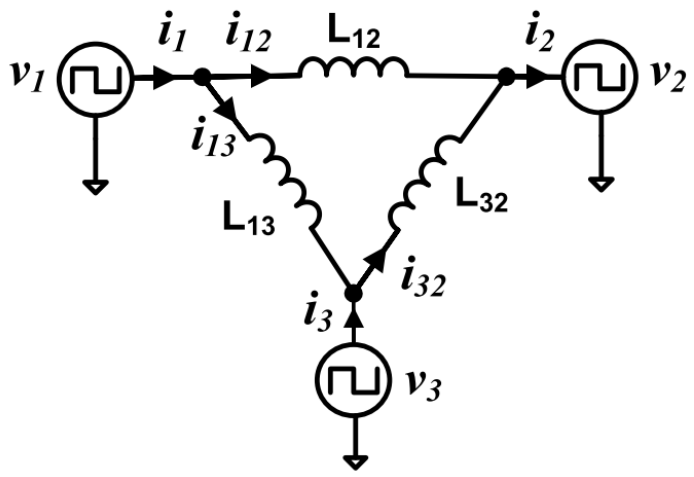

Figure 4. Simplified delta structure of a TAB converter

other port on the output side is connected with an inverter, and then connected to a Nano-grid after all.

The operation of a $\mathrm{TAB}$ converter is similar to a $\mathrm{DAB}$ converter. The converter can be expressed by a simplified delta structure as Figure 4 shows, which contains square-wave voltage sources and a set of inductors [11]. Different from DAB converter, the voltage sources are phase shifted by two certain phase angles. The two controllable phase-shift variables determine the power flow direction between load side and sources side. The current flow through each leg, as showed in Figure 4, can be expressed by (1), and the current waveform associated with the voltage waveform on each port can be achieved. Figure 5 illustrates the current on port 1 .

$$
\begin{aligned}
& i_{1}=i_{12}+i_{13} \\
& i_{2}=i_{12}+i_{32} \\
& i_{3}=i_{32}-i_{13}
\end{aligned}
$$

As mentioned before, there are two controllable variables for a TAB converter. Also, the different relations among the voltage amplitude of three voltage supply lead to different operation conditions. The combination of phase-shift angles and voltage amplitude result in a total of 36 different operation modes [12]. Figure 6 illustrates six possible operation modes, under the condition of $v_{1}>v_{3}>v_{2}$.

It can be concluded from Figure 6 that the current waveform is changed due to the different values of phase-shift angles, which results the different output power flow from $v_{1}$. Similar waveforms exist for other voltage conditions, which have been illustrated in Equation 2 .

$$
\begin{aligned}
& v_{1}>v_{2}>v_{3} \\
& v_{1}>v_{3}>v_{2} \\
& v_{2}>v_{1}>v_{3} \\
& v_{2}>v_{3}>v_{1} \\
& v_{3}>v_{1}>v_{2} \\
& v_{3}>v_{2}>v_{1}
\end{aligned}
$$




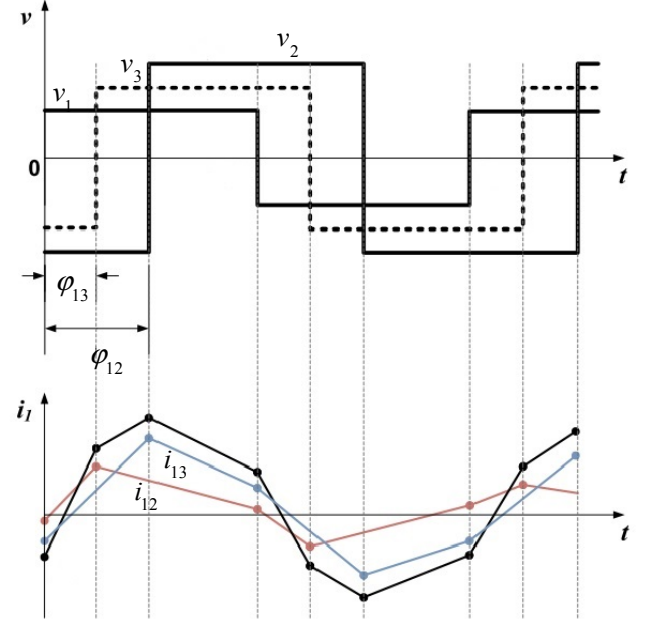

Figure 5. Current waveform on Port 1 of a TAB converter
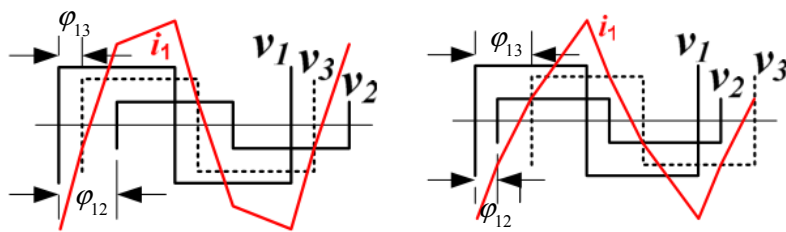

$\varphi_{12}>\varphi_{13}>0$

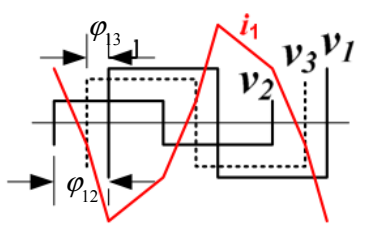

$\varphi_{13}>\varphi_{12}>0$

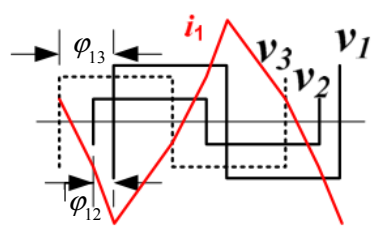

$\varphi_{12}>0, \varphi_{13}<0$

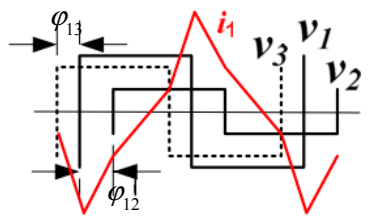

$\varphi_{12}>0, \varphi_{13}<0$

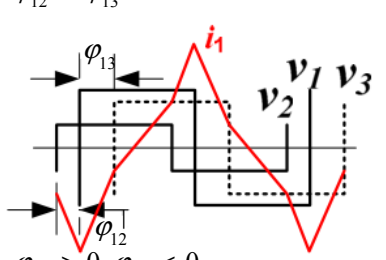

$\varphi_{13}>0, \varphi_{12}<0$

Figure 6. Six different operation modes of a TAB converter under $v_{1}>v_{3}>v_{2}[12]$

Based on the current derivation above, the power flow through each inductor can be expressed by the following equation [13].

$$
\begin{aligned}
& P_{12}=\frac{V_{1} V_{2}}{n_{2} \omega L_{12}} \varphi_{12}\left(1-\frac{\left|\varphi_{12}\right|}{\pi}\right) \\
& P_{23}=\frac{V_{2} V_{3}}{n_{2} n_{3} \omega L_{23}}\left(\varphi_{13}-\varphi_{12}\right)\left(1-\frac{\left|\varphi_{13}-\varphi_{12}\right|}{\pi}\right) \\
& P_{31}=-\frac{V_{3} V_{1}}{n_{3} \omega L_{31}} \varphi_{13}\left(1-\frac{\left|\varphi_{13}\right|}{\pi}\right)
\end{aligned}
$$

Where $\varphi_{12}$ and $\varphi_{13}$ represent the phase shift angle; $n_{2}$ and $n_{3}$ are the equivalent turn ratios illustrated in the simplified delta circuit in Figure 4; $\omega=2 \pi f_{s}$ and $f_{s}$ is the switching frequency of the converter. It can be concluded that the power flow can be controlled by changing the phase shift angles or changing the switching frequency of the converter.

It can be easily concluded that the power flow at each port is a combination of the power flows through each associated branches. Assume that the system is losses, thus the power at each port can be obtained.

$$
\begin{aligned}
& P_{1}=P_{12}-P_{31} \\
& P_{2}=P_{23}-P_{12} \\
& P_{3}=P_{31}-P_{23} \\
& P_{1}+P_{2}+P_{3}=0
\end{aligned}
$$

\section{B. Lithium-Ion Battery}

A lithium-Ion battery series is employed in this project acting as an ESS connected to port 3 . In order to derive an equivalent high frequency model of the battery that will be used later to estimate the losses of the battery series, the impedance of one battery cell is measured. The nominal capacity of the tested battery cell is $3.2 \mathrm{Ah}$ and the nominal cell voltage is $3.3 \mathrm{~V}$.

As [10] presented, the high frequency model of the battery cell is illustrated in Figure 7, which includes two resistors and two inductors. The measurement of the battery cell impedance under different state of charge (SOC) has been represented in [14]. It can be concluded from Figure 7 that the equivalent impedance of the battery cell, which is shown in (5).

$$
Z_{\text {battery-cell }}=R_{1}+s L_{1}+\frac{l_{2} s R_{2}}{L_{2} s+R_{2}}
$$

In order to derive the four parameters of the high frequency model, an advanced vector fitting method is employed [15][17]. The frequency response $f(s)$ of the cell is approximated, which is shown in (6).

$$
f(s) \approx \sum_{m=1}^{N} \frac{c_{m}}{s-a_{m}}+d+s e
$$

The coefficients showed in (6) can be obtained by comparing (5) and (6). The estimated parameters for the battery cell high frequency model are illustrated in Table 1.

It should be noted that the employed ESS includes 8 modules connected in series, and 15 parallel strings are included in each module, in which 15 battery cells are connected in series. Therefore, the total impedance of the ESS can be calculated by (7).

$$
Z_{E S S}=\frac{15 \times Z_{\text {battery-cell }}}{15} \times 8=8 \times Z_{\text {battery-cell }}
$$




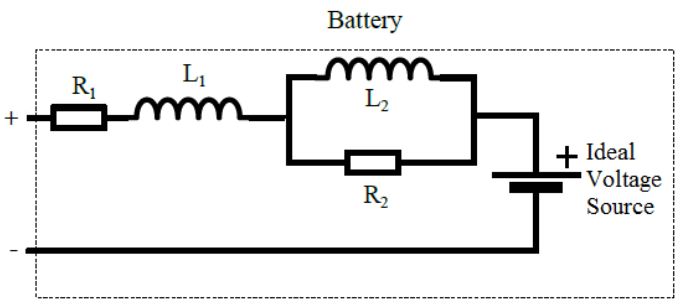

Figure 7. Battery cell high frequency model

TABLE I. ESTIMATED BATTERY CELL PARAMETERS

\begin{tabular}{|c|c|c|c|}
\hline Parameter & $\mathbf{1 0 0} \%$ SOC & $50 \%$ SOC & Unit \\
\hline$R_{1}$ & 50.66 & 115.0 & \multirow{2}{*}{$m \Omega$} \\
\cline { 1 - 3 }$R_{2}$ & 28.4 & 6.9 & \\
\cline { 1 - 2 }$L_{1}$ & 2.6847 & 2.4307 & \multirow{2}{*}{$\mu H$} \\
\cline { 1 - 2 }$L_{2}$ & 0.13364 & 0.61274 & \\
\hline
\end{tabular}

The calculated ESS impedance will be used in Section III to estimate the battery losses under different switching frequency; also, it will be used to calculate the overall converter efficiency.

\section{Power Devices Employed}

Current commercially available $\mathrm{SiC}$ MOSFET power modules are in medium voltage $(1.2 \mathrm{kV}$ or $1.7 \mathrm{kV}$ maily) and medium power range (several tens of kilowatts). In order to compare the device performance in TAB converter between SiC-based devices and Si-based devices, same package for IGBT and SiC MOSFET power module have been chosen [18], [19], which provide a lot of flexibility to design the converter. It would be easier to replacethe Si-based IGBT with SiC MOSFET power module with the same package. To compare the parameters of the devices, some selected values have been illustrated in Table II. The selected values are tested under $V_{D S} / V_{C E}=600 \mathrm{~V}, I_{D S} / I_{C E}=120 \mathrm{~A}, R_{G}=2 \Omega$ for $\mathrm{SiC}$ MOSFETs and $1.6 \Omega$ for $\mathrm{Si}$ IGBT, $T_{j}=25^{\circ} \mathrm{C}$, unless the test conditions are specified in the table.

The first two selected parameters $V_{\text {th }}$ and $C_{i s s} / C_{i e s}$ are directly related to the switching speed of the devices. It can be seen that the threshold voltage for Si IGBT is much higher than SiC MOSFET, which means the turn-on delay for $\mathrm{Si}$ IGBT will larger than $\mathrm{SiC}$ MOSFET, results in a lower switching speed. The input capacitance of the devices affects the required power coming from the gate driver to turn-on the device. It can be noted that the input capacitance of Si IGBT is almost three times than the SiC MOSFET, which means the required power from the gate driver will be larger compared with the one used for SiC MOSFET.
TALBE II. SELECTED TYPICAL PARAMETERS FOR SIC MOSFET POWER MODULE

\begin{tabular}{|c|c|c|c|}
\hline Selected Parameters & $\mathrm{SiC}$ & $\mathbf{S i}$ & Unit \\
\hline$V_{t h}$ & 2.6 & 6.2 & $V$ \\
\hline$C_{i s s} / C_{i e s}$ & 6.3 & 18 & $n F$ \\
\hline$E_{\text {total }} / E_{\text {off }} @ R_{G}=2 \Omega$ & 2.4 & 9.1 & \multirow{3}{*}{$m J$} \\
\hline$E_{\text {total }} / E_{\text {off }} @ 120 \mathrm{~A}, 25^{\circ} \mathrm{C}$ & 2.4 & 4 & \\
\hline$E_{\text {total }} / E_{\text {off }} @ 120 \mathrm{~A}, 125^{\circ} \mathrm{C}$ & 2.1 & 5.7 & \\
\hline
\end{tabular}

TABLE III. EXPERIMENTAL SETUP PARAMETERS

\begin{tabular}{|c|c|c|}
\hline Parameter & Value & Unit \\
\hline \multicolumn{3}{|c|}{ TAB Converter } \\
\hline Power & 30 & $k W$ \\
\hline Port 1 & 750 & $V$ \\
\hline Port 2 & 750 & $V$ \\
\hline Port 3 & 375 & $V$ \\
\hline DC-link capacitance & 420 & $\mu F$ \\
\hline Series inductance & 38 & $\mu H$ \\
\hline \multicolumn{3}{|c|}{ Lithium-Ion Battery } \\
\hline Rated Voltage & 384 & $V$ \\
\hline Maximum Voltage & 438 & V \\
\hline Capacity & 18.4 & $k W h$ \\
\hline
\end{tabular}

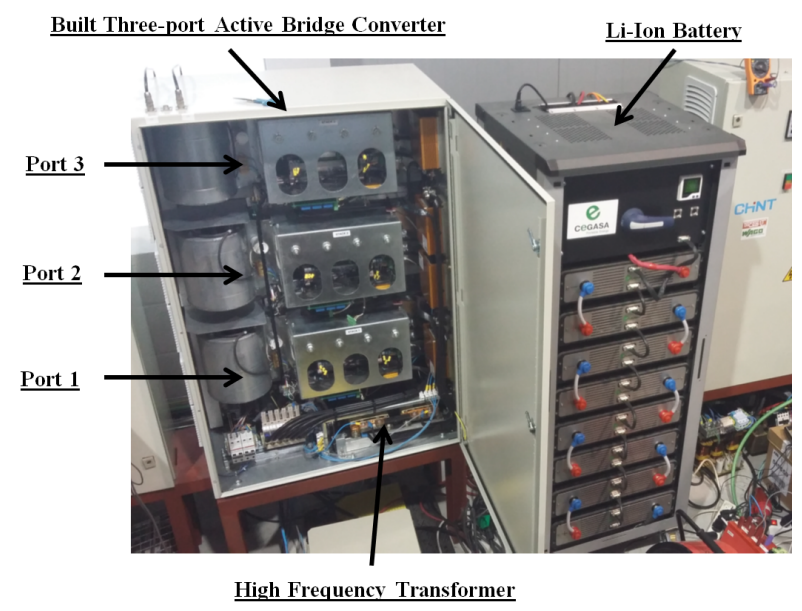

Figure 8. Experimental setup

The switching energies at different conditions are also compared in Table II. The total switching energy and turn-off energy are compared for SiC MOSFET and Si IGBT, respectively. For Si IGBT, only turn-off energy is provided due to the existence of tail current during turn-off process, which is believed to nominate the switching losses of $\mathrm{Si}$ IGBT. Obviously, the total switching energy for $\mathrm{SiC}$ MOSFET is lower than the turn-off energy of Si IGBT. It is expected that the performance of the built $\mathrm{TAB}$ converter 
using $\mathrm{SiC}$ MOSFETs will be improved with a higher efficiency.

\section{EXPERIMENTAL RESULTS}

For the experimental validation, the setup for both $\mathrm{SiC}$ based TAB converter and Si-based approach has been shown in Figure 8 . The parameters of the experimental setup have been illustrated in Table III. It should be noted that the built converter is for experimental validation propose, the maximum power is set to be $30 \mathrm{~kW}$ and will be extended to $150 \mathrm{~kW}$ later for actual micro-grid application. The exact same design has been used to build both $\mathrm{SiC}$-based $\mathrm{TAB}$ converter and $\mathrm{Si}$ one, which will stress the efficiency improvement brought by $\mathrm{SiC}$ based power devices.

Moreover, the efficiency values are obtained by measured voltage and current waveforms with a scope, measured data was stored and processed offline to calculate the efficiency. The same voltage/current probes have been used to eliminate the errors brought by measurement system when comparing the system efficiency for SiC-based TAB and Si-based approach.

\section{A. Power Converter Efficiency Comparison}

The converter is tested with a power supply connected to Port 1 and a resistor $(12 \Omega$, rated at $18 \mathrm{~kW})$ connected to Port 3 . Power is controlled flows from Port 1 to Port 3 . As mentioned in Section II, the power flow in a TAB converter can be controlled by changing the phase shift angles or changing the switching frequency of the converter. The phase shift angle $\varphi_{13}$ is adjusted to keep the power constant when swapping the switching frequency of the converter ( $20 \mathrm{kHz}$ to $40 \mathrm{kHz}$ for Sibased converter and $20 \mathrm{kHz}$ to $60 \mathrm{kHz}$ for $\mathrm{SiC}$-based converter). The applied power to the converter starts from $1 \mathrm{~kW}$ and tested up to $11 \mathrm{~kW}$. Figure 9 shows the efficiency comparison between $\mathrm{SiC}$-based TAB converter and Si-based one.

It can be concluded that an approximately $2 \%$ of efficiency increment is brought by SiC MOSFETs, which is a result of the much lower switching losses of SiC MOSFETs. Moreover, the efficiency for SiC-based converter keeps stable when switching

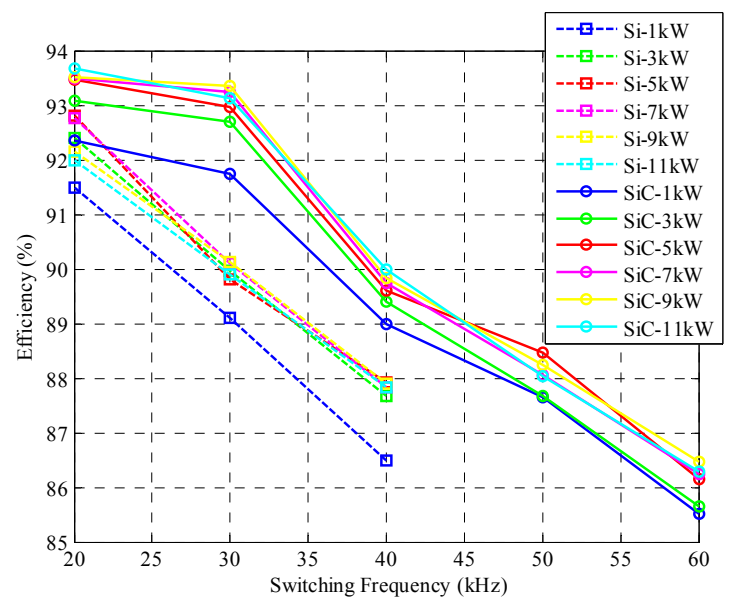

Figure 9. SiC vs Si: power converter overall efficiency comparison, power flows from Port 1 to Port 3 frequency increases from $20 \mathrm{kHz}$ to $30 \mathrm{kHz}$. Compared with $\mathrm{SiC}$-based converter, the efficiency for Si-based approach decreases dramatically with more than 5\% when switching frequency increases from $20 \mathrm{kHz}$ to $40 \mathrm{kHz}$. It can be seen that from $20 \mathrm{kHz}$ to $60 \mathrm{kHz}$, the efficiency for SiC-based converter decreases by approximately $6 \%$. The extra losses are considered to be brought by devices and magnetics in the converter. It is believed that a new design of the magnetics as well as the passive components would provide a higher efficiency to the SiC-based converter under such high switching frequency.

It should be noted that the converter is tested under nominal voltage $750 \mathrm{~V}$ when power is $11 \mathrm{~kW}$, while the other power level is tested below the nominal voltage, results in a higher efficiency for $11 \mathrm{~kW}$ compared with the other power levels.

\section{B. Power Converter with Battery Efficiency Comparison}

In order to evaluate the battery performance and its influence to the converter efficiency at higher switching frequency, the battery is connected to Port 3 as a power supply and a resistor $(36 \Omega$, rated at $18 \mathrm{~kW})$ is connected to Port 1 .

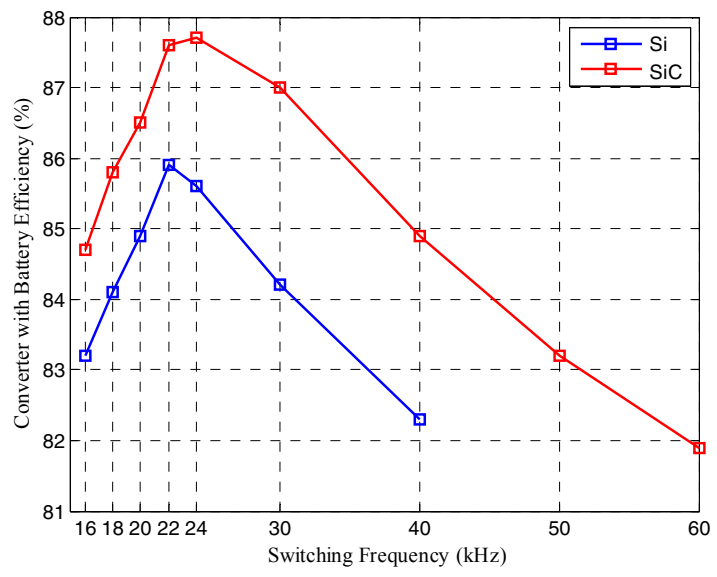

Figure $10 . \mathrm{SiC}$ vs $\mathrm{Si}$ : power converter with battery efficiency comparison
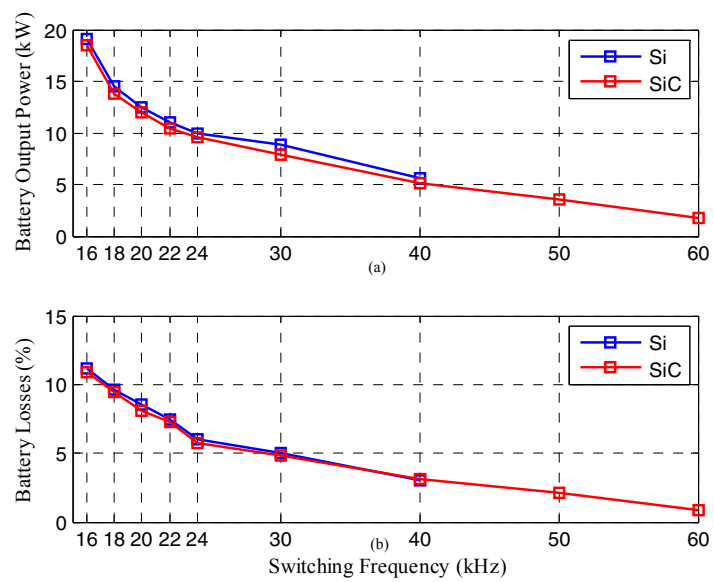

Figure 11. $\mathrm{SiC}$ vs $\mathrm{Si}$, top (a) battery output power verses switching frequency, bottom (b) battery losses verses switching frequency 
Moreover, the switching frequency of the converter is swapped from $16 \mathrm{kHz}$ to $40 \mathrm{kHz}$ and $16 \mathrm{kHz}$ to $60 \mathrm{kHz}$ for Sibased converter and SiC-based converter, respectively. The SOC of the battery is kept constant at $80 \%$ due to the impedance of the battery depends on the SOC of the battery, as mentioned in Section II. The voltages and currents are measured at the output side of the battery, which is the input of Port 3, and at Port 1 to get the power value; the output power of battery is estimated within the battery high frequency model. Different from the previous test in last sub-section, the phase-shift angle is kept constant when swapping the switching frequency. Figure 10 presents the efficiency of the converter with battery connected for SiC-based TAB and Sibased version, Figure 11 (a) shows the calculated battery output power and Figure 11 (b) shows the normalized losses of battery itself at different switching frequency.

It can be seen that the existence of battery pulls down the overall converter efficiency significantly due to losses of the battery. However, it can be seen that at lower switching frequencies (e.g. $16 \mathrm{kHz}$ to $22 \mathrm{kHz}$ ) the losses of the battery is the nominating part, and the system efficiency is increasing with the decrease of the battery losses. With the increase of switching frequency, the switching losses and magnetics losses become dominate, which results in an efficiency drop.

On the battery point of view, a reverse trend is observed from Figure 11(b) that the battery losses are reduced by $8 \%$ as a result of the increased frequency (from $16 \mathrm{kHz}$ to $60 \mathrm{kHz}$ ), as already explained, due to the inductive behavior of the battery. It can be concluded that the increased switching frequency has a positive impact on the battery side that the losses of the battery itself will reduce. It should be noted that the output power of the battery ideal voltage source is decreasing with the increase of the switching frequency as shown in Figure 11 (a), which is the result of the constant phase shift. If the switching frequency is increased with a constant phase-shift, the output power will reduce, as (3) shows.

\section{CONCLUSION}

This paper presents a performance comparison between $\mathrm{SiC}$ MOSFETs power module and Si IGBT in a TAB converter application. Moreover, the influence of higher switching frequency in battery side is also tested and discussed. As shown in the experimental results section, the converter efficiency is increased by $2 \%$ due to application of $\mathrm{SiC}$ MOSFETs. As a benefit of higher switching speed potential of SiC MOSFETs, the battery losses is reduced by approximately $8 \%$ when the switching frequency increases from $16 \mathrm{kHz}$ to $60 \mathrm{kHz}$. Additional experiments with higher power (up to $150 \mathrm{~kW}$ ) as well as the improvement of SiC MOSFETs on soft-switching strategies and the optimization of the magnetics/passive components are the ongoing research activities. Moreover, some studies on the reliability and robustness of $\mathrm{SiC}$ MOSFETs with discrete package have been published [20], but little work has been done on the power module level. The short-circuit test as well as the unclamped inductive switching (UIS) test are the ongoing activities as well.

\section{REFERENCES}

[1] X. She A. Q. Huang and R. Burgos "Review of solid state transformer technologies and their applications in power distribution system" IEEE J. Emerg. Sel. Topics Power Electron. vol. 1 no. 3 pp. 186-198 Sep. 2013.

[2] S. De Breucker, "Impact of dc-dc Converters on Li-ion Batteries," Ph.D. dissertation, Katholieke Universiteit Leuven, 12-Dec-2012.

[3] C. Gu Z. Zheng L. Xu K. Wang and Y. Li "Modeling and control of a multiport power electronic transformer (PET) for electric traction applications" IEEE Trans. Power Electronics vol. 31 no. 2 pp. 915-927 Feb. 2016.

[4] Z. Ding C. Yang Z. Zhang C. Wang and S. Xie "A novel soft-switching multiport bidirectional dc-dc converter for hybrid energy storage system" IEEE Trans. Power Electronics vol. 29 no. 4 pp. 1595-1609 Apr. 2014.

[5] P. Roussel, "SiC market and industry update," presented at the Int. SiC Power Electron. Appl.Workshop, Kista, Sweden, 2011.

[6] J. Biela M. Schweizer S. Waffler and J. W. Kolar "SiC versus SiEvaluation of potentials for performance improvement of inverter and dc-dc converter systems by $\mathrm{SiC}$ power semiconductors" IEEE Trans. Ind. Electron. vol. 58 no. 7 pp. 2872-2882 Jul. 2011.

[7] A. Hussein and A. Castellazzi, "Performance Benchmark of Si IGBTs vs. SiC MOSFETs in Small-scale Wind Energy Conversion System” in 17th International Conference on Power Electroncis and Motion Control, Sep 2016.

[8] B. Zhao Q. Song and W. Liu "Experimental comparison of isolated bidirectional dc-dc converters based on all-Si and All-SiC power devices for next-generation power conversion application" IEEE Trans. Ind. Electron. vol. 61 no. 3 pp. 1389-1393 Mar. 2014.

[9] D. De, A. Castellazzi and A. Lamantia, "1.2kW Dual-Active Bridge Converter using SiC Power MOSFETs and Planar Magnetics", in International Power Electroncis Conference, 2014, pp. 2503-2510.

[10] J.Wang, K. Zou, C. Chen, and L. Chen, "A high frequency battery model for current ripple analysis," in Applied Power Electronics Conference and Exposition (APEC), 2010 Twenty-Fifth Annual IEEE. IEEE, 2010, pp.676-680.

[11] H. Tao A. Kotsopoulos J. Duarte and M. Hendrix "Transformer-coupled multiport ZVS bidirectional dc-dc converter with wide input range" IEEE Trans. Power Electronics vol. 23 no. 2 pp. 771-781 Mar. 2008.

[12] R. Yapa and A. Forsyth "Extended soft switching operation of the triple active bridge convereter" Power Electronics Machines and Drives (PEMD 2012) 6th IET International Conference On. IET 2012.

[13] Haimin Tao, "Integration of sustainable energy sources through power electronic converters in small distributed electricity generation systems," Ph.D. dissertation, Technische Universiteit Eindhoven, 21-01-2008.

[14] P. Garcia, S. Saeed, A. Rodriguez and J. Garcia, "Switching frequency optimization for a Solid State Transformer with Energy Storage Capabilities", in IEEE Energy Conversion Congress \& Expo, Sep 2016.

[15] B. Gustavsen and A. Semlyen, "Rational approximation of frequency domain responses by Vector Fitting," IEEE Trans. Power Delivery, vol. 14, no. 3, pp. 1052-1061, July 1999.

[16] B.Gustavsen, "Improving the pole relocating properties of vector fitting," IEEE Trans. Power Delivery, vol. 21, no. 3, pp. 1587-1592, July 2006.

[17] D. Deschrijver, M. Mrozowski, T. Dhaene, and D. De Zutter, "Macromodeling of multiport systems using a fast implementation of the vector fitting method," IEEE Microwave and Wireless Components Letters, vol. 18, no. 6, pp. 383-385,June 2008.

[18] Fuji Electric, Datasheet of 2MBI200HH-120-50 [Online]. Available: http://www.fujielectric.com.cn/products/semiconductor/model/igbt/2pac k.html

[19] CREE, Datasheet of CAS120M12BM2 [Online]. Available: www.cree.com

[20] R. Gianpaolo, A. Fayyaz, M. Riccio, L. Maresca, G. Breglio, A Castellazzi, A. Irace, "A Comprehensive Study of Short-Circuit Ruggedness of Silicon Carbide Power MOSFETs," IEEE Journal of Emerging and Selected Topics in Power Electronics, vol. 4, no.3, pp.978-987, May 2016 